\title{
Design and synthesis of a photoswitchable guanidine catalyst
}

\author{
Philipp Viehmann and Stefan Hecht ${ }^{*}$
}

\section{Full Research Paper}

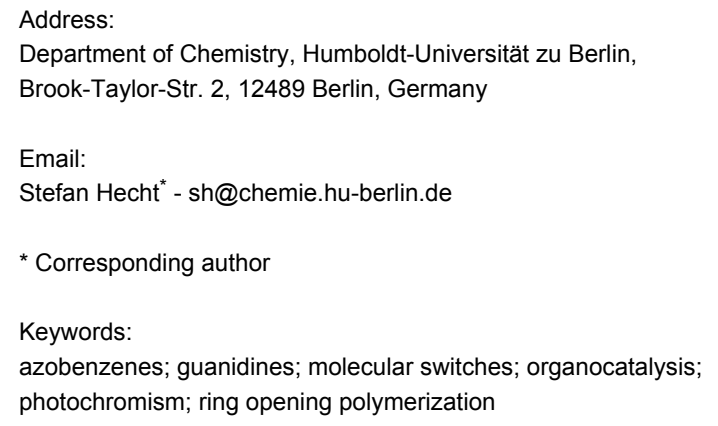

\begin{abstract}
A novel design as well as a straight-forward synthesis for a photoswitchable guanidine catalyst is reported. Intense studies of the photochromic properties demonstrated the reversible switchability of its photosensitive azobenzene moiety. Its activity in the ringopening polymerization (ROP) of rac-lactide was investigated as well. The obtained results are discussed, and an additional guanidine was synthesized and utilized in the ROP of rac-lactide in order to explain the findings.
\end{abstract}

\section{Introduction}

The macroscopic properties of a given polymer, e.g., the glasstransition temperature, morphology, density and tensile strength, are strongly dependent on its microscopic structure. It is well known that this structure, which is characterized by parameters such as molecular weight and distribution, composition, regiochemistry and stereochemistry (tacticity), critically depends on the interaction between catalyst and monomer during the polymerization process. Gaining control over these processes has therefore been the subject of intense research efforts. With this in mind, chemists have recently started to incorporate gates into catalysts to control their action through external stimuli. The use of light as such an external, noninvasive, and well-controlled stimulus perhaps represents the most attractive approach to controlling catalytic activity and selectivity due to the attainable high spatio-temporal resolution [1]. In order to create such photoswitchable catalysts [2], photochromic moieties [3-5] have to be incorporated into the catalyst system [6-13]. To the best of our knowledge, successful examples of photoswitchable catalysts for the ring-opening polymerization (ROP) of lactide have not been reported thus far, although a remarkable example of a photocaged system has been reported [14].

Metal-based catalysts as well as organocatalysts have been widely studied in the ROP of lactide [15]. Guanidines, and especially 1,5,7-triazabicyclo[4.4.0]dec-5-ene (TBD), have 


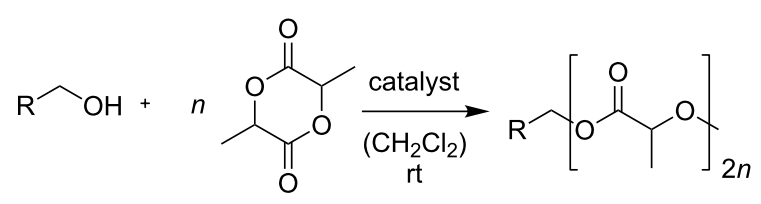

catalysts:<smiles>C1CN=C2NCCCN2C1</smiles>

TBD

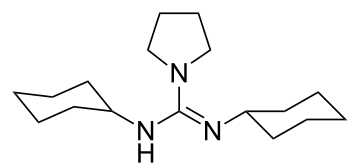

1
Scheme 1: Ring-opening polymerization (ROP) of lactide with TBD or the acyclic guanidine 1 as catalysts $[16,18]$. proven to be very powerful in this context (Scheme 1) [16]. However, due to the discussion of several polymerization mechanisms [17], TBD is a difficult target for the incorporation of photoresponsive switches. Recent work indicates that the activation mechanism for acyclic guanidines, such as guanidine $\mathbf{1}$ (Scheme 1), is strongly dependent on the formation of hydrogen bridges to monomer and initiator [18]. Note that with pyrenebutanol as the initiator, 200 repeat units are grown within $20 \mathrm{~s}$ by using TBD as the catalyst, while $1 \mathrm{~h}$ is needed with the acyclic guanidine $\mathbf{1}$ to reach the same average chain length.

Based on this finding it should be possible to create a catalyst that may be deactivated by formation of intramolecular hydrogen bonds to an acceptor (A) and activated by light-triggered dissociation of such intramolecular hydrogen bonds (Scheme 2). Herein, we report the synthesis of the first photoswitchable guanidine, as well as its photochromic behavior.

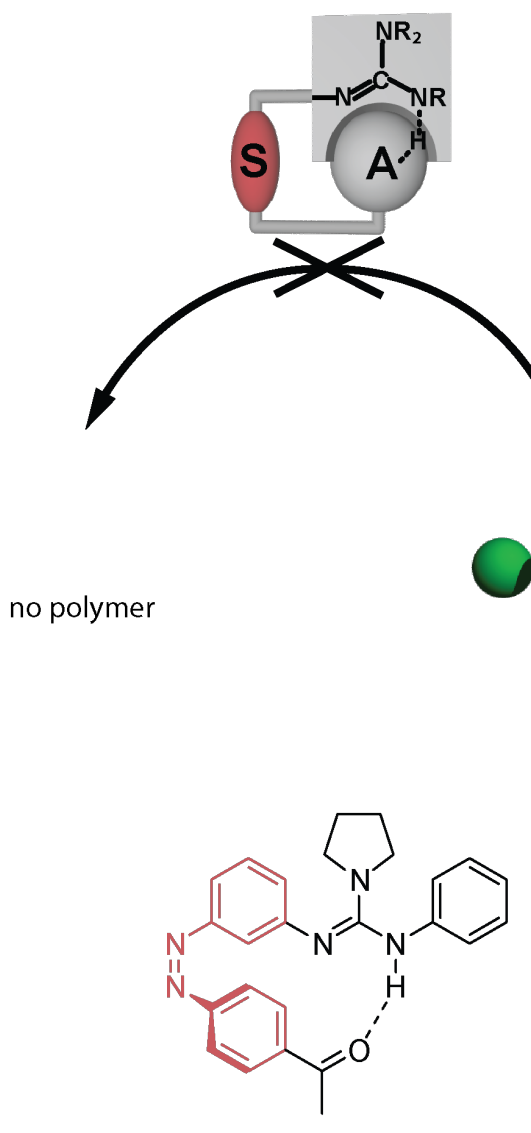

$2 z$
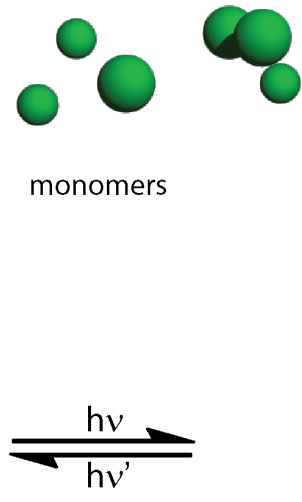

polymer

monomers 
Upon irradiation, the incorporated azobenzene is supposed to undergo photoinduced $E \rightarrow Z$ isomerization, allowing the Brønsted acceptor, in this case a ketone, to form a hydrogenbridge to the proton of the guanidine.

\section{Results and Discussion}

The synthesis of guanidine $\mathbf{2}_{\boldsymbol{E}}$ (Scheme 3 ) was accomplished starting from phenylisocyanate (3) and 3-nitroaniline (6). The latter was converted by known procedures into its corresponding nitroso derivative 7 [19], followed by a Mills coupling with 4-aminoacetophenone (8) to give azobenzene 9 in $93 \%$ yield over two steps. Nitroazobenzene 9 was transformed into its amino derivative $\mathbf{1 0}$ by catalytic hydrogenation. Note that under the employed conditions reduction of the azobenzene function of compound 9 was observed, yet the formed hydrazine analogue reoxidized in situ upon being stirred under atmospheric conditions (air). The free amine $\mathbf{1 0}$ finally reacts with the in situ prepared Vilsmeyer salt $\mathbf{5}$ to provide the desired target compound $\mathbf{2}_{\boldsymbol{E}}$. The therefore necessary urea $\mathbf{4}$ can be obtained from the addition of pyrrolidine to phenylisocyanate (3).

The structure of guanidine $\mathbf{2}_{\boldsymbol{E}}$ was proven by NMR spectroscopy, HRMS, as well as by single-crystal X-ray structure analysis (Figure 1). To our knowledge, this is the first example of an X-ray analysis of an acyclic guanidine-methanol adduct, clearly proving the existence of a hydrogen bridge between an alcohol $\mathrm{OH}$ function and the nitrogen of the guanidine. This significantly supports the mechanism of alcohol activation in the polymerization process. Additionally, the crystal structure confirms the validity of our concept, illustrating the azobenzene's utilization as a spacer by spatial separation of the guanidine core and carbonyl function.

In order to utilize the incorporated light-sensitive azobenzene functionality, the photochromic behavior of guanidine 2 was

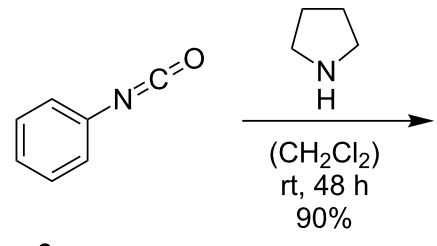

3 $90 \%$<smiles>CCO[Sb](=O)(O[Na])O[Na]</smiles>
6<smiles>CC(=O)c1ccc(/N=N/c2cccc(/N=C(\Nc3ccccc3)N3CCCC3)c2)cc1</smiles>

4<smiles>O=C(Nc1ccccc1)N1CCCC1</smiles>

(toluene)
$60^{\circ} \mathrm{C}, 1 \mathrm{~h}$

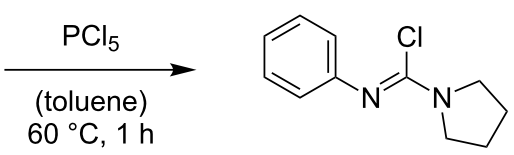

5

5<smiles>CC(=O)c1ccc(N=Nc2cccc(N=Nc3cccc([N+](=O)[O-])c3)c2)cc1</smiles> 

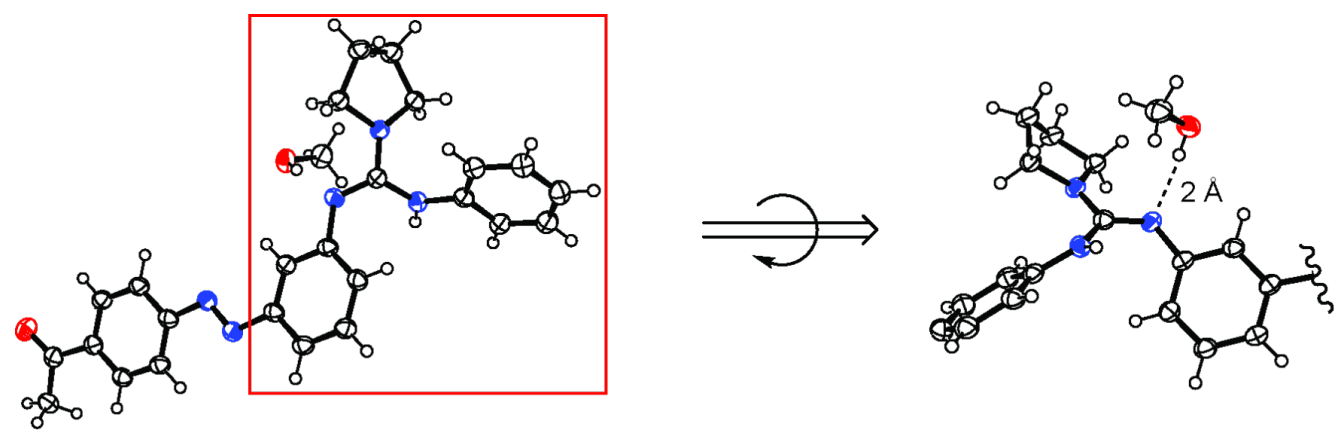

Figure 1: ORTEP image of the single-crystal X-ray structure of guanidine $\mathbf{2}_{E}$, as well as a rotated close-up of the guanidine moiety, showing $50 \%$ thermal ellipsoids (CCDC 891016).

investigated by UV-vis spectroscopy (Figure 2). The UV-vis spectrum of guanidine $\mathbf{2}_{\boldsymbol{E}}$ in acetonitrile exhibits the expected behavior, similar to the unsubstituted parent azobenzene, i.e., a low intensity $\mathrm{n} \rightarrow \pi^{*}$ band in the visible region and a much stronger $\pi \rightarrow \pi^{*}$ band in the UV region of the spectrum. Note that the $n \rightarrow \pi^{*}$ band partially overlaps with the $\pi \rightarrow \pi^{*}$ band in the $(E)$-isomer. Upon irradiation at $340 \mathrm{~nm}$ (Figure 2a), the $\pi \rightarrow \pi^{*}$ band of the isomer $\mathbf{2}_{E}$ at $326 \mathrm{~nm}$ vanishes and the $\pi \rightarrow \pi^{*}$ band of the isomer $2_{Z}$ with its blue-shifted maximum at $273 \mathrm{~nm}$ appears. The content of isomer $\mathbf{2}_{Z}$ in the photostationary state (pss) was determined to amount to $61 \%$ by UPLC using a detection wavelength on the isosbestic point $(290 \mathrm{~nm})$. Based on this a)

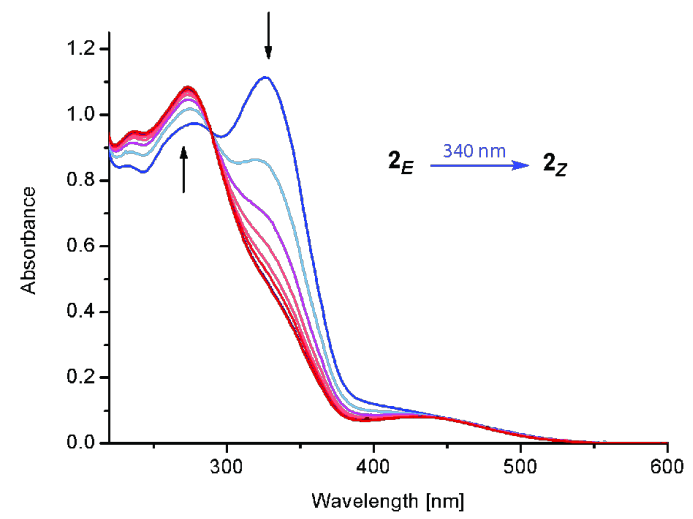

c)

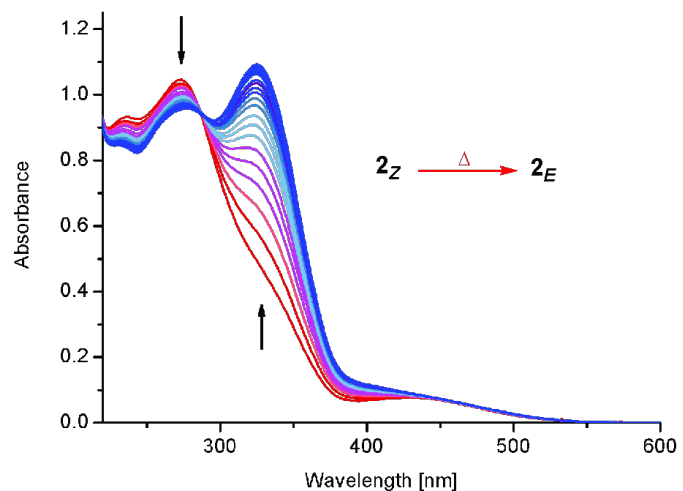

b)

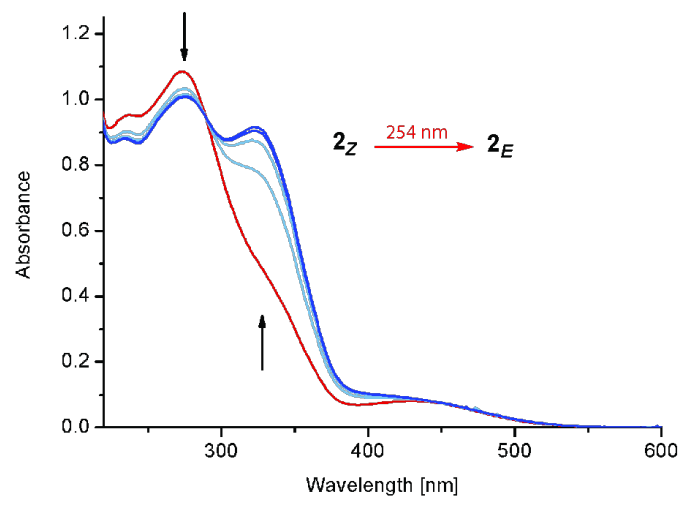

d)

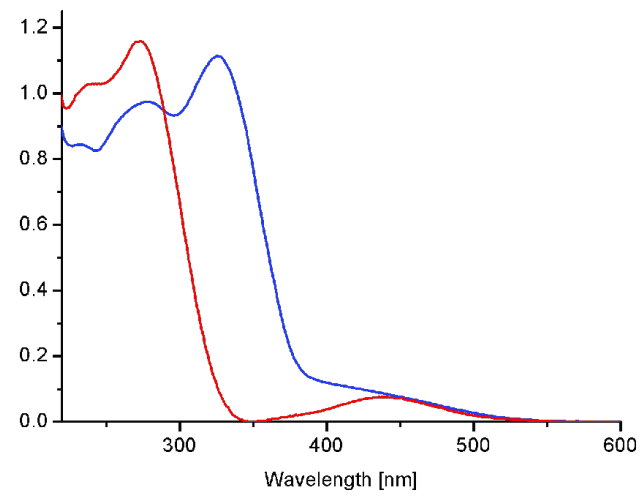

Figure 2: UV-vis spectra of guanidine 2 in acetonitrile, $c=3.9 \cdot 10^{-5} \mathrm{~mol} / \mathrm{L}$. (a) $E \rightarrow Z$ isomerization with irradiation at $340 \mathrm{~nm}$, $25^{\circ} \mathrm{C}$; (b) $Z \rightarrow E$ isomerization with irradiation at $254 \mathrm{~nm}, 25^{\circ} \mathrm{C}$; (c) thermal $Z \rightarrow E$ isomerization at $40{ }^{\circ} \mathrm{C}$; (d) spectra of $\mathbf{2}_{E}$ (blue) and $\mathbf{2}_{Z}$ (calculated, red). 
data, the UV-vis spectrum of the isomer $\mathbf{2}_{\boldsymbol{Z}}$ was calculated (Figure 2d), assuming that the total absorption is the sum of the partial absorptions. Obviously, the significant hypsochromic shift of the $\pi \rightarrow \pi^{*}$ band leads to a separation of the $n \rightarrow \pi^{*}$ and $\pi \rightarrow \pi^{*}$ bands for the (Z)-isomer. As expected, an inverse behavior is observed upon irradiation at $254 \mathrm{~nm}$, inducing photoisomerization of guanidine $\mathbf{2}_{Z}$ back to its precursor $\mathbf{2}_{E}$ (Figure $2 \mathrm{~b}$ ). The amount of isomer $\mathbf{2}_{\boldsymbol{E}}$ in the resulting pss was determined to be $94 \%$. The same nearly quantitative $Z \rightarrow E$ photoisomerization, giving $92 \%$ of $\boldsymbol{2}_{\boldsymbol{E}}$ in the pss, is obtained upon irradiation at 430 $\mathrm{nm}$.

Related to the supposed function of guanidine as a switchable catalyst, these experiments demonstrate the reversible photoisomerization of the azobenzene moiety. Nevertheless, the switching properties can still be improved, in particular to obtain a pss with higher $(Z)$-content in the $E \rightarrow Z$ photoisomerization. Besides the photo-induced $Z \rightarrow E$ isomerization, the thermal back-reaction of guanidine $\mathbf{2}_{\boldsymbol{Z}}$ was examined as well (Figure 2c). Based on the measured UV-vis and UPLC data and assuming a first-order rate law, the rate constant of the thermal $Z \rightarrow E$ isomerization at $40{ }^{\circ} \mathrm{C}$ was determined to be $\left.k_{(40}{ }^{\circ} \mathrm{C}\right)=$ $6.3 \cdot 10^{-5} \mathrm{~s}^{-1}$ corresponding to a half-life of $\tau_{1 / 2}=3 \mathrm{~h}$. The measurement at slightly elevated temperature $\left(40{ }^{\circ} \mathrm{C}\right)$ was necessary since at $25^{\circ} \mathrm{C}$ the thermal half-life increases significantly (Supporting Information File 1, Figure S-5), leading to distinct difficulties in its determination, e.g., the evaporation of the solvent and the resulting change in concentration. Therefore, the rate constant and thermal half-life at $25{ }^{\circ} \mathrm{C}$ could only be estimated by using data points from the first $36 \mathrm{~h}$ (Supporting Information File 1, Figure S-6) yielding $k_{\left(25^{\circ} \mathrm{C}\right)}=4.2 \cdot 10^{-6} \mathrm{~s}^{-1}$ and $\tau_{1 / 2}=46 \mathrm{~h}$. Consequently, the half-life significantly exceeds the expected duration of the polymerization reaction [18], rendering guanidine 2 very attractive for this purpose. In summary, the observed photochromic behavior detailed above indicates promising properties for the utilization of guanidine $\mathbf{2}$ as a photoswitchable catalyst.

In order to determine the activity of the catalyst, the crystalbound methanol was removed and guanidine $\mathbf{2}_{\boldsymbol{E}}$ was utilized in the ROP of rac-lactide with pyrenebutanol as the initiator. In a catalyst/initiator/monomer ratio of 1:1:100 no significant formation of polylactide was observed at $\mathrm{rt}$ even after $48 \mathrm{~h}$. The absence of reactivity for guanidine $\mathbf{2}_{\boldsymbol{E}}$ in the ROP of rac-lactide may have various origins. First of all, it is obvious that in comparison with catalytically active guanidine $\mathbf{1}$, the two cyclohexane substituents on the nitrogen atoms of guanidine are replaced by aromatic residues, which, at least in one case, is necessary for connecting the photochromic azobenzene moiety to the guanidine core. This replacement most likely results in a significant reduction of the basicity of guanidine. Additionally, the acceptor ketone moiety itself may interact with the initiator or the active end of the polymer chain, thereby interfering with catalysis. In order to examine the latter, guanidine $\mathbf{1 1}$ was synthesized from Vilsmeyer salt $\mathbf{1 3}$ and aniline and tested in the ROP of rac-lactide (Scheme 4). The morpholino substituent was introduced to improve the crystallization behavior of guanidine and should not affect the polymerization.

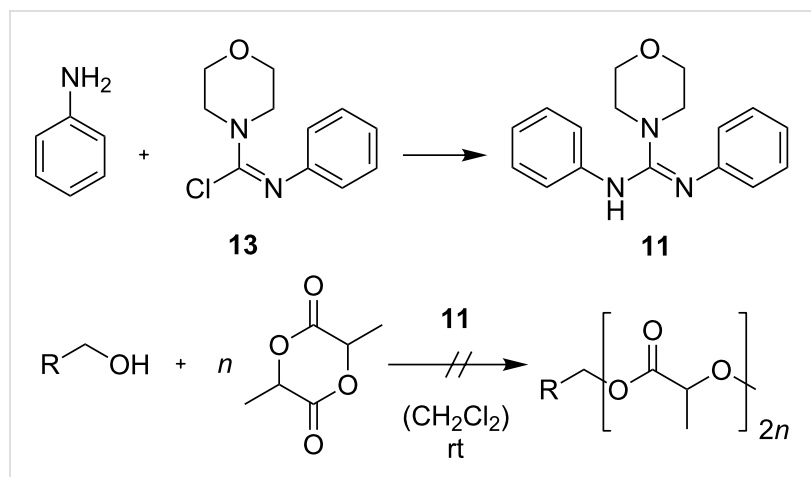

Scheme 4: Guanidine 11 as a catalyst in the ROP of rac-lactide (catalyst/initiator/monomer ratio $=10: 1: 100$ ).

In a catalyst/initiator/monomer ratio of 10:1:100 with pyrenebutanol as initiator no significant formation of polylactide was observed at $\mathrm{rt}$ even after $48 \mathrm{~h}$. This indicates that the catalytic inactivity of guanidine $\mathbf{2}_{E}$ is indeed caused by the guanidine core itself. Besides the previously mentioned basicity issue, a possible reason for this behavior may be discerned from the single-crystal X-ray structure analysis of guanidine $\mathbf{2}_{\boldsymbol{E}}$. It can be seen that, in contrast to the supposed polymerization mechanism (Figure 3a) [18], the lone pair of the nitrogen and the hydrogen of the adjacent nitrogen are not arranged in a parallel manner, i.e., unidirectional facing the substrates (Figure $3 b$ ). If the observed conformation is not caused by stacking effects in the solid state and prevails in solution, it may substantially lower the catalytic activity of the guanidines $\mathbf{2}_{\boldsymbol{E}}$ and $\mathbf{1 1}$.
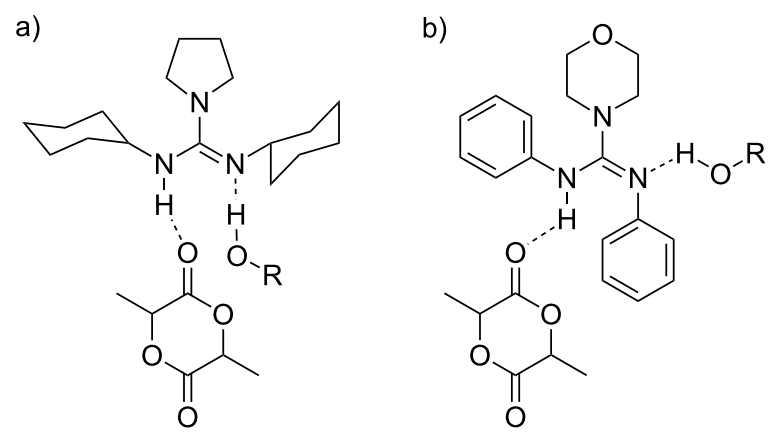

Figure 3: Supposed intermediates resulting from either a cyclohexanesubstituted guanidine (a) [18] or an aromatic substituted guanidine (b) with an alcohol and lactide. 


\section{Conclusion}

In summary, we developed a new approach to the design and synthesis of the novel, photoswitchable guanidine 2. After detailed investigation of its photochromic properties and demonstrating its reversible, light-induced switchability, we started to investigate the reasons for its inactivity in the ROP of lactide. Our efforts are now directed toward the improvement of the design of the catalyst by exchanging one aromatic residue with an alkyl substituent to improve the basicity of guanidine, as well as by introducing sterically crowded substituents or ring constraints in order to direct the position of the relevant lone pair of guanidine as well as the $\mathrm{NH}$-function.

\section{Supporting Information}

The crystal structure has been deposited at the Cambridge Crystallographic Data Centre and allocated the deposition number CCDC 891016

\section{Supporting Information File 1}

Experimental details and spectra.

[http://www.beilstein-journals.org/bjoc/content/

supplementary/1860-5397-8-209-S1.pdf]

\section{Acknowledgements}

We thank Stefan Mebs (HU Berlin) for carrying out the singlecrystal X-ray analysis. Generous support by the German Research Foundation (DFG via SPP 1178) and the European Science Foundation (ESF via P2M) is gratefully acknowledged. We thank BASF AG, Bayer Industry Service, and Sasol Germany for donations of chemicals.

\section{References}

1. Russew, M.-M.; Hecht, S. Adv. Mater. 2010, 22, 3348-3360. doi:10.1002/adma.200904102

2. Stoll, R. S.; Hecht, S. Angew. Chem., Int. Ed. 2010, 49, 5054-5075. doi:10.1002/anie.201000146

3. Dürr, H.; Bouas-Laurent, H., Eds. Photochromism: Molecules and Systems, Revised Edition ed.; Elsevier: Amsterdam, 2003.

4. Feringa, B. L., Ed. Molecular Switches, 2nd ed.; Wiley-VCH: Weinheim, Germany, 2001.

5. Crano, J. C.; Guglielmetti, R. J., Eds. Organic Photochromic and Thermochromic Compounds; Plenum Publishers: New York, 1999.

6. Peters, M. V.; Stoll, R. S.; Kühn, A.; Hecht, S. Angew. Chem., Int. Ed. 2008, 47, 5968-5972. doi:10.1002/anie.200802050

7. Stoll, R. S.; Hecht, S. Org. Lett. 2009, 11, 4790-4793. doi:10.1021/ol902166a

8. Stoll, R. S.; Peters, M. V.; Kuhn, A.; Heiles, S.; Goddard, R.; Bühl, M.; Thiele, C. M.; Hecht, S. J. Am. Chem. Soc. 2009, 131, 357-367. doi:10.1021/ja807694s

9. Ueno, A.; Takahashi, K.; Osa, T. J. Chem. Soc., Chem. Commun. 1981, 94-96. doi:10.1039/C39810000094
10. Lee, W.-S.; Ueno, A. Macromol. Rapid Commun. 2001, 22, 448-450. doi:10.1002/1521-3927(20010301)22:6<448::AID-MARC448>3.0.CO;2 $-W$

11. Würthner, F.; Rebek, J., Jr. Angew. Chem., Int. Ed. Engl. 1995, 34, 446-450. doi:10.1002/anie.199504461

12. Würthner, F.; Rebek, J. J. Chem. Soc., Perkin Trans. 2 1995, 1727-1734. doi:10.1039/P29950001727

13. Cacciapaglia, R.; Di Stefano, S.; Mandolini, L. J. Am. Chem. Soc. 2003, 125, 2224-2227. doi:10.1021/ja029331x

14. Sun, X.; Gao, J. P.; Wang, Z. Y. J. Am. Chem. Soc. 2008, 130, 8130-8131. doi:10.1021/ja802816g

15. Dechy-Cabaret, O.; Martin-Vaca, B.; Bourissou, D. Chem. Rev. 2004, 104, 6147-6176. doi:10.1021/cr040002s

16. Pratt, R. C.; Lohmeijer, B. G. G.; Long, D. A.; Waymouth, R. M.; Hedrick, J. L. J. Am. Chem. Soc. 2006, 128, 4556-4557. doi:10.1021/ja060662+

17. Chuma, A.; Horn, H. W.; Swope, W. C.; Pratt, R. C.; Zhang, L.; Lohmeijer, B. G. G.; Wade, C. G.; Waymouth, R. M.; Hedrick, J. L.; Rice, J. E. J. Am. Chem. Soc. 2008, 130, 6749-6754. doi:10.1021/ja0764411

18. Zhang, L.; Pratt, R. C.; Nederberg, F.; Horn, H. W.; Rice, J. E.; Waymouth, R. M.; Wade, C. G.; Hedrick, J. L. Macromolecules 2010, 43, 1660-1664. doi:10.1021/ma901776x

19. Priewisch, B.; Rück-Braun, K. J. Org. Chem. 2005, 70, 2350-2352. doi:10.1021/jo048544x

\section{License and Terms}

This is an Open Access article under the terms of the Creative Commons Attribution License (http://creativecommons.org/licenses/by/2.0), which permits unrestricted use, distribution, and reproduction in any medium, provided the original work is properly cited.

The license is subject to the Beilstein Journal of Organic Chemistry terms and conditions:

(http://www.beilstein-journals.org/bjoc)

The definitive version of this article is the electronic one which can be found at: doi:10.3762/bjoc. 8.209 